\title{
Coercive paternalism and the intelligence continuum
}

\author{
NATHAN COFNAS * \\ Balliol College, Oxford, OX1 3BJ, UK
}

\begin{abstract}
Thaler and Sunstein advocate 'libertarian paternalism'. A libertarian paternalist changes the conditions under which people act so that their cognitive biases lead them to choose what is best for themselves. Although libertarian paternalism manipulates people, Thaler and Sunstein say that it respects their autonomy by preserving the possibility of choice. Conly argues that libertarian paternalism does not go far enough, since there is no compelling reason why we should allow people the opportunity to choose to bring disaster upon themselves if sometimes they will make the wrong decision. She defends 'coercive paternalism'. The present paper argues that errors in reasoning are not due only to cognitive biases. People also make errors because they have an insufficient level of general intelligence. Intelligence is distributed on a continuum. Those who fall on higher levels of the continuum have greater abilities, in certain contexts, to reason about both their own and others' interests. Coercive paternalism may sometimes be appropriate to prevent less intelligent people from engaging in self-destructive behavior due to errors of reasoning.
\end{abstract}

Submitted 7 December 2017; revised 18 January 2018; accepted 1 February 2018

\section{Weighing the value of autonomy against the benefits of paternalism}

Paternalism involves using force or manipulation (of varying types and degrees) to change someone else's behavior for their own benefit (Dworkin, 2017). Many people strongly oppose paternalism by governments on the grounds that it does not respect our autonomy. Given how much we value personal freedom, this is understandable. We can easily accept that governments must infringe on individuals' autonomy to prevent them from harming others indeed, no society would be possible without formal or informal laws against certain kinds of other-regarding harm. But given the psychic harm we

\footnotetext{
*Correspondence to: Nathan Cofnas. Email: nathan.cofnas@balliol.ox.ac.uk
} 
experience when we are coerced for any reason, many people balk at the idea that they should be subjected to coercion for their own purported benefit.

According to Mill's famous Harm Principle, the only legitimate reason to exercise power over a mentally competent adult is to prevent harm to others (Mill, 1859/1991, p. 14). One of the chief reasons he gives to justify this principle is epistemic: people are (almost) always in a better position to know what is good for themselves than some would-be paternalist.

But Mill's epistemic argument seems to be predicated on an overly optimistic picture of how people reason and act (Sunstein, 2014, pp. 4-7). It assumes that people are 'Homo economicus'. Homo economicus reasons and acts according to the dictates of rational choice theory. It does not reason or act differently depending upon the way in which different options are worded or physically presented to them. Their capacity to assess what option will maximize their utility is virtually unlimited, as is their stock of willpower to follow the utility-maximizing course of action (Thaler \& Sunstein, 2008).

Research in psychology and behavioral economics over the past few decades shows decisively that humans are not Homo economicus. As documented by Ariely (2008), Kahneman (2011) and others, our choices are influenced by many factors that have no relevance to the outcomes we are considering. Even when we do succeed in determining what course of action will best serve our interests, we frequently procrastinate, are derailed by temptation or, for various other reasons, fail to act as we know we ought to. The results from psychology and behavioral economics undermine Mill's argument that paternalism will almost never work because people, so long as they have access to the relevant information, are virtually always well suited to know what is in their own best interests and to act accordingly. In some cases, a neutral observer is in a better position to recognize what is in someone else's interests and potentially to prevent them from engaging in self-destructive behavior.

In light of this, Thaler and Sunstein (2008) propose what they call 'libertarian paternalism'. The libertarian paternalist manipulates the 'choice architecture' - that is, the conditions under which people make and follow through on their choices - so that our cognitive biases will incline us toward those decisions and actions that are best for us. For example, when people must select a healthcare or retirement plan, they are very likely to go with the default option even if the default option was itself selected randomly. Sometimes people fail to make a choice at all if doing so requires an active effort, even when the stakes are high. The libertarian paternalist would simply make the default option (and the option assigned to those who do not make a selection) for each person that which is most likely to be best for them, as determined by a fully informed third party. Or, since people are more likely to select food at a cafeteria if it is at eye 
level, the libertarian paternalist would display the healthiest options at this most advantageous position, relegating less healthy options to the lower racks. Since libertarian paternalism merely 'nudges' people in the direction that is best for them without eliminating the self-destructive options, Thaler and Sunstein argue that it "respect[s] freedom of choice" (p. 146). It should be acceptable even to those who object to 'hard' paternalism that eliminates certain options and thus fails to respect our autonomy.

Conly (2013, p. 32), however, argues that libertarian paternalism does not really respect people's autonomy. After all, it is motivated by the idea that people should not be "left to their own devices in deciding what to do." At the same time, while libertarian paternalism may sometimes 'nudge' people toward better decisions, it still allows them to choose badly and suffer. In other words, libertarian paternalism violates people's autonomy and also falls short of bringing about the good results that would be guaranteed by less restrained paternalistic interventions. As she puts it, "[w]e may end up with neither of the valuable things libertarian paternalism hoped to promote."

If we are justified in infringing - or even morally obligated to infringe - on people's autonomy in order to save them from their own seriously destructive choices, there seems to be no compelling reason to stop at libertarian paternalism. We do not need to go to such great lengths to preserve the possibility of choice when this just means leaving people with the option to bring disaster upon themselves. We ought to save people by means of coercive paternalism. Of course, when people are coerced, they may resent it and feel deprived of liberty. "On the other hand," Conly argues, "being addicted to cigarettes or obese, or bankrupt, or too poor to retire, much less to retire as we like, are frustrating, liberty-inhibiting conditions, too" (p. 24). Coercing people imposes a psychological cost on them. Why not just weigh this cost against the benefits of paternalistic coercion? Being prevented from buying cigarettes may be a bad experience for someone who wants to smoke. A drawn-out, painful, premature death from cancer is also a bad experience. Why can't the coercive paternalist legislator, in determining what is best for people, prohibit actions the future effects of which are worse that the pain of being coerced now?

To reiterate, the coercive paternalist should acknowledge that infringing on people's autonomy can be a bad thing because people (often) do not like it. The coercive paternalist just resists assigning excessive value to individual freedom. Our view of human rationality - inherited from Enlightenment thinkers - is that we think and act as Homo economicus. On that view, individual freedom is of preeminent importance because each individual knows what is best for themself and acts accordingly. But, again, we are not Homo economicus. 
Perhaps (one could argue) personal autonomy has some special status that makes it incomparably more valuable than the benefits that would follow from paternalistic intervention. This argument rests on shaky ground. After all, we restrict people's autonomy all the time - to protect other people's interests. This is not controversial at all. Conly (2013, pp. 34-36) suggests that there is no reason why coercing people should be acceptable to prevent harm to others but not to themselves - unless we maintain a false Enlightenment picture of people as unable to harm themselves through their own free choice.

Conly's arguments are compelling: cognitive biases often cause people to fail to make choices and act in their own best interests, and coercive paternalism is sometimes an appropriate way to help them. However, cognitive biases are not the only reason that people fail to act as Homo economicus. Homo economicus is supposed to have virtually unlimited capacities for accurately processing information. In reality, people are not only limited in this respect - there is also a great deal of variation within the human population. Some people have a much greater capacity for general reasoning ability, which has potential implications for paternalism that are not discussed by either Conly or Thaler and Sunstein.

Conly and Thaler and Sunstein emphasize that the cognitive biases to which coercive or libertarian paternalism, respectively, is a response are (nearly) human universals. Conly (2013, p. 2) says:

there is nothing in the existence of widely shared weaknesses in reasoning to suggest that one group should have power over others. These cognitive deficits are a general human phenomenon, not the peculiar property of one kind of person, so there is nothing to justify giving one group power over others on an autocratic basis.

Legislators can design paternalistic laws to help people overcome these biases not because the legislators are not subject to them, too, but because, being in a "relatively objective position," they will not be "tempted by the rewards of a poor decision" (p. 10). Paternalistic legislators can act under circumstances where their cognitive biases do not corrupt their reasoning, even if they have exactly the same reasoning dispositions as those who would benefit from their paternalism.

Conly notes a general potential objection to paternalism: it seems to "posit significant inequality among humans, inequality of a sort that could justify a class or caste system." If one class of people makes rules for another class of people regarded as less able to make decisions, this would be "undemocratic in a deep sense, dangerous in numerous ways, and for these reasons at least, morally unacceptable." She expounds: 
In fact, however, it is not an assumption of superiority, but of shared fallibility, that moves us to paternalism, and no assumption is made about the superiority of one group of people over another. While it is true that some pictures of paternalistic government have suggested that the more able will be in charge of the welfare of the less able, our present understanding of cognitive bias doesn't support the view that one group is entitled to that kind of authority over others. Not only does it not support a class division, it positively undercuts the grounds for such a division. There is no evidence of demarcation in education or IQ that distinguishes who is, and who is not, prone to the sorts of errors which can prevent us from reaching our goals. This should hardly be surprising. We know, after all, that CEOs and government experts have made mind-boggling errors in their economic calculations, and presumably we are individually familiar with intelligent people who seem incapable of thinking straight in some instances of decision making. (pp. 37-38)

The present paper reviews evidence that, contra Conly, IQ differences do correspond to significant differences in the ability to assess our interests in certain contexts. Furthermore, there is strong empirical evidence that much of the irrational behavior - including smoking and poor eating choices - that Conly (and Thaler and Sunstein) attributes to cognitive biases is due to a large extent to low general reasoning ability. Although cognitive biases are virtually universal, people with low general intelligence are much more likely to adopt diets that cause obesity and make other decisions that Conly argues should be prohibited by coercive paternalism. For example, in regard to smoking (whose relationship with intelligence is more complicated, as shall be discussed later), she says that "a number of errors in judgment [are involved]: people use time discounting to undervalue how much the future matters; anchor the use of an irrelevant starting point to make comparisons, so that they judge that since the first ten cigarettes haven't hurt them then the next ten years' worth won't either," and so on (p. 22). "Educating people out of error is not easy, when errors arise in significant part from cognitive bias" (p. 25). "Educating people [about the dangers of smoking] simply isn't all that effective, because in some areas we are relatively ineducable" (p. 33). But this is a mistake. Some people are more educable than others, and some have indeed been educated about smoking. The view that because ten cigarettes have not hurt then ten years of smoking will not hurt either is more likely to be adopted by those with lower levels of general intelligence. Intelligent people (such as 'government experts') can also make mistakes for any number of reasons - cognitive biases, a failure to apply their intelligence correctly, etc. but they have a greater capacity to reason correctly about their (or others') interests when doing so requires assessing complex evidence. 
What about the idea that paternalism predicated on intellectual differences among people is "undemocratic in a deep sense, dangerous in numerous ways"? Conly herself says that "[r]ealism cannot be degrading, and treating people in accordance with their actual abilities is not insulting or disrespectful. Recognition of our actual status is all respect can call for" (p. 42). If people are poised to bring disaster upon themselves, it should not matter whether or not the cognitive or intellectual traits that underlie their behavior are also possessed by the paternalist intervener. Conly's own arguments in favor of coercive paternalism do not lose their force if the tendency to choose poorly in certain circumstances is not universal.

\section{The intelligence continuum and its implications for well-being}

Some influential philosophers have taken a dichotomous view of human intellectual competence according to which all those above a certain threshold have an effectively equal decision-making capacity. Hobbes claimed that all "men" (by which he presumably meant all people who are not overtly impaired) have almost equal capacities to form good judgments:

Nature hath made men so equall, in the faculties of body, and mind; as that though there bee found one man sometimes manifestly stronger in body, or of quicker mind than another; yet when all is reckoned together, the difference between man, and man, is not so considerable, as that one man can thereupon claim to himselfe any benefit, to which another may not pretend, as well as he. (1651/1996, ch. 13, para. 1)

Mill (1859/1991, p. 14) made a simple distinction between "human beings in the maturity of their faculties," who are qualified to make decisions, and those who have not attained such maturity due to age or impairment. Several decades of work in psychometrics challenges such dichotomous pictures of human intelligence.

Wikler (1979) acknowledges that intelligence is distributed on a continuum, but defends a competent/incompetent dichotomy. Any particular task, he says, requires a threshold level of intelligence to perform. Vis-à-vis that task, people have either more or less than the threshold level, and so are either competent or not. Variation in intelligence among those above or below the threshold has no bearing on their competence or incompetence, respectively. Tasks facing the citizens in modern society can all be performed by people of 'normal' intelligence. Therefore, he concludes, all people of at least normal intelligence (the non-mentally handicapped) are equally intellectually equipped to act responsibly, in contrast to those of below normal intelligence. Those of below normal intelligence may be paternalistically controlled, but not those who 
are normal or above average. Citing and accepting Wikler's argument, Feinberg (1986, p. 30) concludes:

It is the threshold conception of natural competence - minimal relevant capability for a task - that is used in stipulations of necessary and sufficient conditions for the sovereign right of self-government ascribed to individuals. Some competent persons are no doubt more richly endowed with intelligence, judgment, and other relevant capabilities than others, but above the appropriate threshold they are deemed no more competent (qualified) than the others at the 'task' of living their own lives according to their own values as they choose.

This and the following section will examine the empirical evidence bearing on the question of whether variation in intelligence within the 'normal' range corresponds with significant differences in capacity to reason about one's own interests.

\section{The theory of general intelligence}

The field of intelligence research was spawned by one momentous discovery, which was the following: people's performance on cognitive tests are positively correlated, regardless of the content of the test (Spearman, 1904, 1927). This is known as the 'positive manifold'. As long as tests require some mental manipulation or the interpretation of information (as opposed to the simple regurgitation of knowledge), people who excel in one domain are relatively more likely to excel in others, without any known exceptions (Carroll, 1993). The correlation among abilities in very different domains is strikingly high. On the Wechsler Adult Intelligence Scale, the correlation between Verbal IQ and Performance IQ (a measure of visuospatial reasoning) is 0.77 (Edmonds et al., 2008, Table 4).

Intelligence researchers can only directly measure specific cognitive abilities. They can test how many digits people can remember and repeat back in reverse order, or how well they can mentally rotate a pictured object to say whether it is the same as another pictured object in a different position. Note that they can do this without resolving the perennial controversy about how to define 'intelligence'. They can objectively study patterns in performance on specific tasks that have objectively right or wrong answers.

Using factor analysis, psychometricians can extract the most general underlying factor that accounts for individual differences in performance on tests of various specific abilities. This general factor is called the ' $g$ factor'. Then, by administering a battery of tests, it is possible to estimate an individual's level of $g$ relative to others in the population. An individual's 'IQ' is an estimate of their $g$. (IQ tests are usually calibrated so that the average score is 100 
and the standard deviation is 15.) An IQ score conveys more information about how an individual will perform on cognitive tests in different domains than does their score on any specific test.

According to one popular opinion, IQ only measures one's ability to take an IQ test. According to another, IQ only measures 'book smarts', which, although real, have little relevance outside the classroom. Decades of empirical evidence undermines both of these popular views. IQ is the best predictor of outcomes in a wide variety of domains both inside and outside academia, from health to driving accidents to job performance (O'Toole, 1990; Gottfredson, 2004a, 2004b; Gottfredson \& Deary, 2004; Haier, 2017).

The question at issue for this paper is whether those with lower levels of $g$ may fail, more often than those with a higher level of $g$, to reason well about what is in their own interests, and benefit from coercive paternalistic intervention by those with higher levels of $g$. It will be argued that the biggest risk factor for engaging in many of the self-destructive behaviors that Conly (2013) suggested should be paternalistically outlawed, such eating too much unhealthy food and running up credit card debt, is low IQ. The following section gives illustrations of how IQ differences correspond to differences in the ability to reason well about the sorts of real-life problems that are relevant to wellbeing and reviews some of the evidence that IQ differences correspond to disparities in actual outcomes. The section after that will consider why, in light of the purpose for which intelligence evolved, intelligence usually but not always protects people from self-destructive choices.

\section{The implications of general intelligence for real-life decision-making}

Citing Stanovich and West (2000), Rachlinski (2006) notes that people with higher IQs are less susceptible to cognitive biases. When faced with complex tasks, those with less general intelligence tend to fall back on intuition, which is dominated by biases. The present section defends a somewhat stronger claim: many of the problems that people must solve to advance their own interests have the form of IQ questions (Gordon, 1997). It is not merely that higherIQ individuals are less susceptible to cognitive biases. When faced with choices that require one to interpret complex evidence or understand cause-and-effect relationships, those with lower IQs may fail to act in their own interests not because of cognitive biases, but because they do not possess the general reasoning ability to process the information.

The American Psychological Association Task Force on Intelligence states: "Individuals differ from one another in their ability to understand complex ideas, to adapt effectively to the environment, to learn from experience, to engage in various forms of reasoning, to overcome obstacles by taking 
thought" (Neisser et al., 1996, p. 77). To understand why variation in general intelligence leads to differences in outcomes outside the classroom, let us turn to data on adult literacy.

The National Adult Literacy Survey (NALS), conducted by the Educational Testing Service under the auspices of the US Department of Education, classifies Americans into five levels of intellectual ability in three domains of problem solving: (a) Prose analysis; (b) Document interpretation; and (c) Quantitative problem-solving. To be classified at any of the five levels within any domain means that one is able to solve problems at a certain level of complexity with no less than $80 \%$ accuracy, without being able to solve problems at the next highest level with such accuracy (Kirsch et al., 2002, p. 71). The best way to illustrate what variation in cognitive ability really means is to look at the level of cognitive functioning associated with these levels. Note that individuals tend to achieve roughly the same level of literacy in all three domains (viz., Prose analysis, Document interpretation and Quantitative problem-solving).

Level 5 (Quantitative): "Using [a] calculator, determine the total cost of carpet to cover a room" (Kirsch et al., 2002, Figure 1); only 5\% of white adults are classified at this level of Quantitative literacy (Kirsch et al., 2002, Figure 1.6).

Level 4 (Document): Use a moderately complicated bus schedule to determine how long you would have to wait for a bus traveling from one city to another after arriving at a specified time; $19 \%$ of adults are classified at this level of Document literacy, with $77 \%$ classified below.

Level 3 (Prose): "Write a brief letter explaining [an] error made on a credit card bill"; $36 \%$ of adults are classified at this level of Prose literacy, with 39\% below.

Level 2 (Document): Figure 1 is an example of a question associated with Document-literacy level 2; $27 \%$ of adults are classified at this level, while $16 \%$ are classified in Document-literacy level 1 and cannot reliably solve problems at the level of complexity demanded by problems such as that in Figure 1.

Level 1 (Document): "Locate [the] expiration date on a driver's license"; $16 \%$ of adults are classified at this level of Document literacy.

The NALS data suggest that $16 \%$ of adults - a very sizable minority - cannot reliably solve problems more complicated than finding the expiration date on a driver's license (Document interpretation level 1). Another $27 \%$ or so can only solve problems requiring elementary inferences (level 2). Only $5 \%$ of adults can reliably figure out, with the aid of a calculator, the price of carpeting for a room (Quantitative problem-solving level 5).

NALS questions are essentially IQ questions, but presented in the form of problems that are encountered in everyday modern life (Gottfredson, 1997, 
You are a marketing manager for a small manufacturing firm. This graph shows your company's sales over the last three years. Given the seasonal pattern shown on the graph, predict the sales for Spring 1985 (in thousands) by putting an " $\mathrm{x}$ " on the graph.

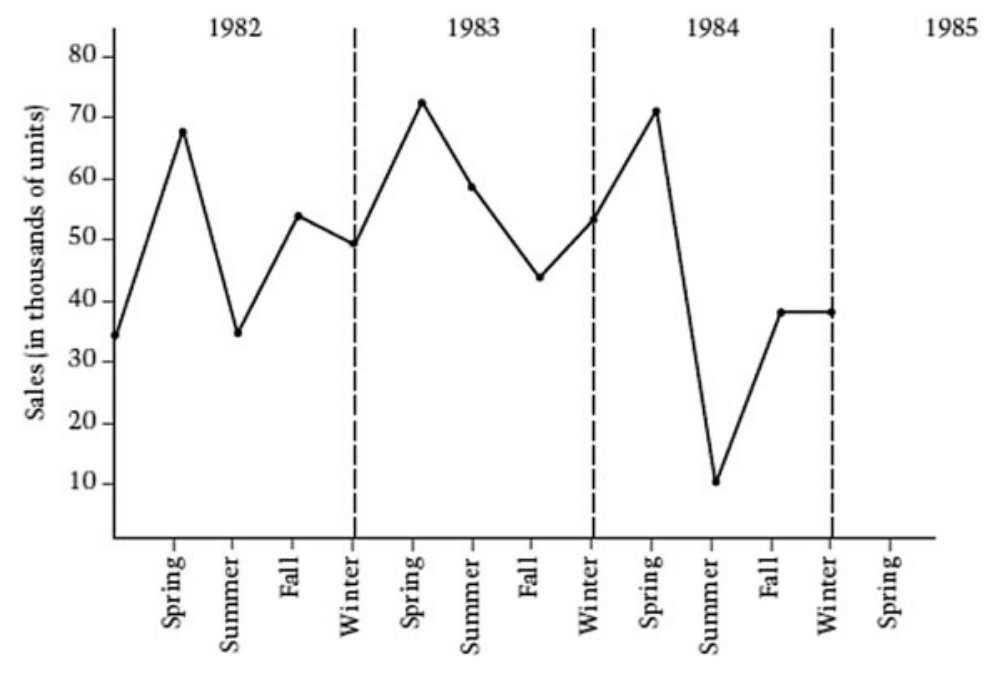

Figure 1. Sample problem associated with the National Adult Literacy Survey Document interpretation level 2. From Kirsch et al. (2002, p. 88). Published 1993, 2002 without copyright by the National Center for Education Statistics, US Department of Education. Reprinted with permission

pp. 109-115, 2004a, p. 177; see also Gordon, 1997). High-IQ individuals who easily solve NALS level 4 and 5 problems may find it difficult to relate to lowIQ individuals for whom such problems pose onerous obstacles in real life (Gottfredson, 2005, p. 177). As noted above, an example of a problem from Document interpretation level 4 is to interpret a moderately complicated, albeit realistic, schedule to figure out how long one has to wait for a bus; $77 \%$ of adults cannot reliably perform this task. Recall that Wikler and Feinberg assumed, without citing empirical evidence, that all but the mentally handicapped are 'competent' to solve problems encountered in modern life. The evidence suggests that this assumption is wrong.

The differences in intellectual ability reflected in the five NALS levels have profound implications for people's ability to solve problems that relate to important real-life outcomes. People in the lower levels face serious challenges 
to making informed decisions related to health, finance and other matters. Williams et al. (1998) found a high correlation between general illiteracy and health illiteracy. Out of 114 diabetics surveyed by them, $51(44.7 \%)$ did not know how to interpret and respond to signs of low blood sugar ("If you suddenly get sweaty, nervous, and shaky, you should eat some form of sugar"). The inability to treat diabetes correctly often results in blindness, amputations and death. Williams et al. $(1998$, p. 170) note: "The fact that patients with diabetes with inadequate literacy had lower scores on knowledge despite having attended formal education classes clearly shows that current educational strategies do not reach the large number of patients with poor reading skills." Out of 2659 outpatients at two public hospitals surveyed by Williams et al. (1995), 41.6\% "were unable to comprehend directions for taking medication on an empty stomach," and $25 \%$ could not correctly interpret an appointment reminder slip. Davis et al. (1990, p. 533) report:

The average reading comprehension of public clinic patients was 6th grade 5 th month. Most tested patient education materials required a reading level of 11th to 14th grade, and standard institutional consent forms required a college-level reading comprehension. In the public clinics there was a gap of more than 5 years between patient reading levels and the comprehension levels required by written patient materials.

Conly $(2013$, p. 44) asks how it could be that, although most everyone "know[s] the basic facts about smoking, including its dangers, its economic costs and its effect on their children," about $20 \%$ of adults in the USA smoke. She suggests that because of cognitive biases "these facts fail to 'take'." As to whether people really "know the dangers of smoking," a "common and perhaps ultimately correct answer is 'kinda'."

Conly's explanation for why people smoke in spite of being exposed to information about its dangers cannot be the whole story. After all, cognitive biases are virtually universal, but some people refrain from smoking because of its dangers. Many people - such as Conly herself $-d o$ fully understand the dangers of smoking. The NALS data suggest a reason why not everyone has achieved the same level of understanding of these facts. For some people, the argument that, because ten cigarettes have not hurt them, ten more years of smoking will be okay (discussed above) is just as compelling as the argument that smokers are statistically much more likely to get terrible diseases after many years. Understanding why the latter argument is better than the former requires a certain level of literacy that not everyone attains. (Still, the association between smoking and IQ is complicated. The following section will present empirical evidence that higher-IQ individuals are more likely to respond to antismoking information campaigns.) 
As Gottfredson (2005, p. 177) says, the problem for people with low levels of literacy "is seldom that they cannot read or write the words, but usually that they are unable to carry out the mental operations the task calls for to compare two items, grasp an abstract concept, provide comprehensible and accurate information about themselves, follow a set of instructions, and so on. This is what it means to have poor 'functional literacy'." In regard to understanding the dangers of smoking, almost everyone can read words about the relevant evidence, but not everyone can correctly interpret those words and assimilate the information and figure out how to act on it to advance their own interests. It is these people who can be said to only 'kinda' understand the dangers of smoking. Those with higher levels of functional literacy, however, are much more likely to genuinely understand the dangers.

Evidence suggests that IQ also has a strong negative association with poor eating choices. People with a lower IQ are much more likely to become obese (Yu et al., 2010; Kanazawa, 2013, 2014). The ability to comprehend and apply information about the importance of diet and exercise for health as with smoking - is related to general cognitive ability, which is not distributed equally among all people.

Intelligence is also related to patient compliance. Depending on the disease and the population, around $25-50 \%$ of patients fail to comply with instructions for taking prescription medication, leading to poor health outcomes for individuals (including death), lost productivity and enormous costs for the healthcare system (Iuga \& McGuire, 2014). About $10 \%$ of hospitalizations and $23 \%$ of nursing home admissions in the USA may be due to patients failing to take medication according to the instructions (Gottfredson, 2004a, p. 187). Studies have found that noncompliance with medical treatment is due mainly to "inability, not unwillingness, to understand and implement the treatments [that] physicians recommend, especially as regimens become more complex" (Gottfredson \& Deary, 2004, p. 3).

In light of the above findings, it should not be surprising that childhood IQ is highly correlated with adult morbidity and mortality (Gottfredson \& Deary, 2004). O'Toole and Stankov (1992) found that each additional IQ point in young (around 18-year-old) Australian military inductees conferred a 1\% lower risk of dying from noncombat-related causes by age 40. In 1932, Scottish schools administered an IQ test to almost every child born in 1921 who was present in school on the day of testing. Deary et al. (2003) found that among 2792 children from Aberdeen, higher-IQ males were more likely to die in combat during World War II, but children with lower IQs were otherwise significantly more likely to die from all causes. Girls who were at least one standard deviation below average were just $71 \%$ as likely as higher-IQ girls to live to age 76 . In spite of the high mortality among intelligent boys during 
World War II, boys who were at least one standard deviation below average were still just $83 \%$ as likely as those with higher IQs to live to 76 .

One interesting finding from the Scottish data is that there was no significant difference in the childhood IQs between 'ever-smokers' and 'never-smokers', but by the 1970s, there was a 5.2 IQ-point average difference between those who were still smoking and those who had quit. In other words, before the dangers of smoking were known (in the 1930s), intelligence was unrelated to choosing to take up smoking. Once the information came out, the intelligent were more likely to change their behavior (Taylor et al., 2003).

A possible confounding factor that could account for at least part of the relationship between IQ and health outcomes is socioeconomic status (SES) - that is, education, income and occupation. Low IQ is statistically associated with low SES, because a high IQ increases the chance of succeeding in education and complex, high-paying jobs require both education and high $g$ (Gottfredson, 2004b). Perhaps those of lower SES are impaired in their ability to lead healthy lifestyles due (at least in part) to low education or income. If they cannot afford expensive health foods or to pursue expensive, healthy hobbies (e.g., yoga), then choosing the healthiest lifestyle does not seem to be an actual option. But studies that have controlled for IQ have generally found education and income to have very small, if any, independent effects on either health knowledge or health outcomes. Beier and Ackerman (2003), for example, found that knowledge of widely publicized health information had a very high correlation with IQ, while neither education nor income predicted knowledge after controlling for IQ. Rates of noncompliance with prescribed medical treatment regimens is much higher in lower-SES groups, and this is related to the complexity of the regimen rather than to economic barriers such as expensive medicine (Gottfredson, 2004a, p. 187). Other studies have found an independent effect of education on making healthy lifestyle choices, but this explains only part of the relationship between IQ and healthy lifestyle (see the extensive discussion in Gottfredson, 2004a).

In summary, everyone has cognitive biases and no one has an unlimited reasoning capacity. Yet those with lower levels of general intelligence have less ability to reason about how to bring about certain outcomes that are important to well-being, such as good health.

\section{Why general intelligence evolved and why the more intelligent sometimes make worse choices}

Humans evolved a high level of general intelligence in order to solve adaptive problems. What kind of adaptive problems? 
When animals face recurrent problems that present themselves in roughly the same form generation after generation, it is possible for the species to evolve an instinctual response: in the presence of stimulus $S$, exhibit response $R$. For example, to solve the adaptive problem 'avoid being bitten by snakes', many animals, including humans, evolved to exhibit an avoidance response when faced with snake-like stimuli.

General intelligence appears to be an adaptation for solving non-recurrent, or 'evolutionarily novel', adaptive problems - problems for which we cannot in principle evolve instincts to solve (Kanazawa, 2004). Humans, as the consummate generalists, face a uniquely large number of evolutionarily novel challenges in their daily lives. Unlike most other animals, we eat completely different species of plants and animals in the various environments in which we live. These foods often must be processed in complicated ways to neutralize poisons or release nutrients. We cannot rely on our instincts to guide us to plants and animals that are nutritious or to inform us about how to process otherwise poisonous foods. Our uniquely complex social environment regularly poses challenges for individuals that arise only once in evolutionary history. We therefore faced intense pressure to evolve high levels of $g$ (Cofnas, 2016).

Based on the fact that human psychological adaptations are tailored to recurrent features of the ancestral environment (on the African savanna) and the hypothesis that $g$ is an adaptation for dealing with evolutionary novelty (i.e., situations and entities that were not regularly present in the African savanna), Kanazawa (2010) proposes what he calls the 'savanna-IQ interaction hypothesis': individuals with high levels of $g$ are more likely than those with lower levels to be able to handle evolutionary novelty - they are more likely to solve problems in evolutionarily novel (but not evolutionarily familiar) contexts and to be attracted to evolutionary novelties. The savanna-IQ interaction hypothesis predicts that intelligent people will be more likely than the less intelligent to espouse evolutionarily novel preferences and values and to participate in evolutionarily novel activities. These predictions have been confirmed in many cases. For example, intelligent people are more likely to be liberal, atheist and vegetarian, and more intelligent men (but not women) are more likely to espouse monogamy as an ideal (Kanazawa, 2010).

Advanced societies are extremely evolutionarily novel. The process of economic and technological development brings us further and further away from (evolutionarily familiar) nature, creating an increasingly artificial environment populated with evolutionarily novel entities, to navigate which requires general intelligence (see Gottfredson, 1997; Kanazawa, 2010). This creates more and more opportunities for high-IQ individuals, as well as more and more serious challenges for lower-IQ individuals. There are a few cases, however, where evolutionary novelties pose a greater challenge for the 
more intelligent. When harmful entities, ideas or practices are evolutionarily novel, they may disproportionately appeal to the intelligent - for example, cigarettes.

Cigarettes are evolutionarily novel, so at first glance the savanna-IQ interaction hypothesis seems to predict that intelligence will be correlated with smoking. In fact, the data do not show a clear pattern. In a sample of young Israeli army recruits, nonsmokers had a mean IQ of 100.7 compared with 89.6 for heavy smokers (Weiser et al., 2010, Table 3). In a sample of male Swedish military conscripts, nonsmokers had an IQ advantage of similar magnitude (Wennerstad et al., 2010). However, in their analyses of large, population-representative data sets from the USA and the UK, Kanazawa and Hellberg (2010) found a small positive association between childhood intelligence and smoking in the former and a small negative association in the latter.

The explanation for these findings seems to be that there are forces working in opposite directions. On the one hand, cigarettes are evolutionarily novel and thus more attractive to the intelligent. On the other hand, evidence about the negative consequences of smoking is more likely to be understood by (and thus to have an effect on) the intelligent. Kanazawa and Hellberg (2010, p. 390) point out that the public antismoking campaigns in the UK have been "far more aggressive and blatant" than those in the USA. And, they say, "government warnings and public campaigns are themselves evolutionarily novel." While health warnings per se may not be evolutionarily novel, the argument against smoking - long-term epidemiological studies find that smoking increases the risk of certain diseases after many years - is probably evolutionarily novel in regard to its level of complexity. More intelligent people are better at assimilating this information, even if the same people tend to have a relatively greater attraction to cigarettes.

Further evidence supports the idea that the intelligent are better at responding to antismoking information. In their analysis of the National Longitudinal Survey of Youth, Herrnstein and Murray (1994, p. 214) found that the higher a woman's IQ, the less likely she is to smoke during pregnancy. While almost all pregnant white women received prenatal care regardless of their intelligence, $51 \%$ of those with IQs $<90$ reported smoking compared with $16 \%$ of those with IQs $>110 ; 0 \%$ of those with IQs $>125$ reported smoking during pregnancy. Any woman who receives prenatal care will be informed by a doctor about the dangers of smoking during pregnancy, so Herrnstein and Murray's findings suggest that the more intelligent women were much more likely to assimilate and act on this information. And, as mentioned in the previous section, Scottish smokers born in 1921 were more likely to quit smoking by the 1970s - when information about the health effects of smoking became known - the more intelligent they were (Taylor et al., 2003). 
The upshot is that certain self-destructive choices, being evolutionarily novel, are more attractive to intelligent than to less intelligent people. However, the intelligent are also more likely to resist the evolutionarily novel temptation in response to information about its dangers.

\section{Implications for policy}

Thaler and Sunstein (2008) and Conly (2013) argue that, because cognitive biases often prevent people from acting in their own interests, it may be appropriate to use nudges or coercion to prevent them from seriously harming themselves. The present paper provided evidence that the tendency to make miscalculations about one's own interests is, in certain contexts, highly related to general intelligence. Some of the self-destructive choices that people make, such as accepting predatory loans, becoming obese or smoking, involve failures of reasoning that are more likely to occur among those with lower levels of $g$. Although all of the coercive paternalistic laws defended by Conly (e.g., banning smoking and predatory lending) are entirely appropriate, the justification for some of them should refer to differences in reasoning ability among people rather than - or perhaps in addition to - universal cognitive biases.

Some of the biases that Thaler and Sunstein and Conly discuss, such as the 'status quo bias', seem to affect many people at all levels of intelligence. Thaler and Sunstein give several specific examples of clearly high-IQ people who procrastinate, fail to save for retirement and so on. The point of this paper is emphatically not to deny that biases can influence the behavior of high-IQ individuals. Libertarian and coercive paternalistic methods should be used to help people across the intelligence spectrum if they are poised to make grave mistakes because of cognitive biases. But certain kinds of mistakes are most often due to low general reasoning ability, and only the intelligent can be deterred by soft-paternalistic information campaigns.

In response to the fact that some people are not as influenced by cognitive biases as others, Rachlinski (2006, p. 224) suggests that paternalists should "attend more closely to individual variations in cognitive style, and perhaps craft legal rules that sort individuals more carefully." Whether some people fail to act in their own interests due to cognitive biases or just lower levels of general intelligence, it may indeed be reasonable for the law, in some contexts, to 'sort individuals' according to whether or what kind of paternalistic help would benefit them. In some cases, however, this may not be practical. Virtually all legislation involves tradeoffs. Legislators must weigh costs and benefits, not attempt to make laws that have no downside under any circumstances. Most smokers may have failed to weigh up the evidence to determine what is in their own best interests. A tiny minority of highly intelligent 
smokers may fully understand the risks and correctly determine that smoking is actually a good strategy for them to advance their personal goals. A blanket ban on cigarettes affects everyone indiscriminately, even the rational smokers. On the other hand, trying to make exceptions for a small minority in the case of a smoking ban would be likely to create chaos. In some other cases, the most effective intervention might involve sorting people and directing paternalistic help in a targeted way. As discussed, patients with low health literacy (which is highly correlated with IQ) are at much greater risk for failing to comply with medical treatments, which can result in serious harm to themselves. It may be appropriate to target patients with low health literacy for certain kinds of paternalistic intervention, which may or may not be coercive, to ensure compliance.

Consider the problem of following a complicated, self-administered medical treatment regimen. As noted earlier, as many as $50 \%$ of patients do not comply with instructions for taking prescription medication (Iuga \& McGuire, 2014), and this is associated with inability, not unwillingness, to understand the instructions (Gottfredson \& Deary, 2004, p. 3). Some coercive measures could greatly benefit patients with low health literacy (i.e., low IQ) without depriving them of too much autonomy. Patients with low health literacy sometimes stop taking their medication if it does not work after a few days, or they stop taking it as soon as it begins to work but before they have taken the full course that is required to prevent a relapse. In such cases, patients could simply be required to notify a health professional (by some convenient method) whenever it is time to take the medication, or else face a financial penalty. But given that a full $25 \%$ of patients in Williams et al.'s (1995) study were unable to interpret an appointment reminder slip, minimally invasive coercive paternalistic measures like this may be effective only for some patients with borderline low health literacy.

Patients who cannot understand how to treat a chronic disease like diabetes how to recognize and respond to signs of low or high blood sugar (Williams et al., 1998; Gottfredson, 2004b) - and who are thereby at risk for blindness, amputations and death may benefit from more intrusive paternalistic intervention. Perhaps a supervisor could be appointed to monitor their eating practices (what they buy at the grocery store, what restaurants they go to) and to assess whether they are following the treatment regimen well enough to prevent disastrous consequences. The supervisor would have the power to forcibly intervene if the patient's noncompliance was great enough to pose serious danger. The most extreme level of intervention could involve compelling the patient to live in an environment where they can be monitored more closely. Morbidly obese patients who do not have the capacity to plan and follow through on a reasonably healthy dietary plan, and who are in great, imminent danger as a consequence, could benefit from the same sort of coercive paternalistic help. 
People with low IQs, especially in the 70s and below, are at great risk of being chronically unemployed, ending up incarcerated and experiencing a variety of other negative outcomes due to their inability to perform the cognitively demanding tasks required to find and hold a job, to foresee the consequences of their actions and so on (Herrnstein \& Murray, 1994; Gottfredson, 1997, 2004b). These people could potentially benefit from the same sort of coercive paternalistic intervention discussed above in connection with medical patients. In the most extreme cases, where they risk falling into uncontrolled drug addiction and homelessness, they could be compelled to live under some degree of supervision.

One concern about coercive paternalistic measures that arises in multiethnic societies is that, because different ethnicities have different mean IQs (Neisser et al., 1996) and have a smaller or larger proportion of their people classified in the bottom NALS levels (Kirsch et al., 2002, Figure 1.6), members of some ethnicities would be subject to paternalistic intervention more often than others. We generally oppose policies that disproportionately adversely affect some groups. (In US law, this is considered especially problematic when the adverse effects are experienced by members of a 'protected class'.) This concern should be neutralized when we consider that paternalistic help is not an adverse effect, but is by definition a benefit. If an intervention is not a benefit to the intended beneficiary, all things considered, then it is ipso facto not paternalistic (at least in its effect).

\section{Conclusion}

If we accept Conly's (2013) idea that coercion can be the right means to prevent people from acting on errors of reasoning, it does not seem to matter whether those errors are rooted in (nearly) universal cognitive biases, below-average intelligence or both. People ought to be saved from disaster even if those who do the saving do not share the same tendencies to make the same sorts of error. This does not mean that those who are higher on the intelligence continuum should micromanage the lives of those who are lower or impose draconian 'paternalistic' punishments on them - that would obviously cause psychic distress to people that would outweigh any potential benefit. However, if people are prone to engage in a highly self-destructive behavior due to an inability to assess complex evidence and the paternalistic remedy is not worse than the disaster it seeks to prevent, coercive paternalism can be called for.

\section{Acknowledgments}

Thanks to Jonathan Anomaly, Rafael De Clercq, Neven Sesardić and two reviewers for Behavioural Public Policy for helpful comments on earlier drafts of this paper. 


\section{References}

Ariely, D. (2008), Predictably irrational: The hidden forces that shape our decisions, New York: HarperCollins.

Beier, M. E. and P. L. Ackerman (2003), 'Determinants of health knowledge: An investigation of age, gender, abilities, personality, and interests', Journal of Personality and Social Psychology, 84: 439-448.

Carroll, J. B. (1993), Human cognitive abilities: A survey of factor-analytic studies, Cambridge, UK: Cambridge University Press.

Cofnas, N. (2016), 'A teleofunctional account of evolutionary mismatch', Biology \& Philosophy, 31 : 507-525.

Conly, S. (2013), Against autonomy: Justifying coercive paternalism, Cambridge, UK: Cambridge University Press.

Davis, T. C., M. A. Crouch, G. Wills, S. Miller and D. M. Abdehou (1990), 'The gap between patient reading comprehension and the readability of patient education materials', The Journal of Family Practice, 31: 533-538.

Deary, I. J., L. J. Whalley and J. M. Starr (2003), 'IQ at age 11 and longevity: Results from a follow-up of the Scottish Mental Survey 1932', in C. E. Finch, J.-M. Robine and Y. Christen (eds.), Brain and longevity, Berlin: Springer.

Dworkin, G. (2017), 'Paternalism', in E. N. Zalta (ed.), Stanford encyclopedia of philosophy (Winter 2017 ed.). https://plato.stanford.edu/archives/win2017/entries/paternalism/

Edmonds, C. J., E. B. Isaacs, P. M. Visscher, M. Rogers, J. Lanigan, A. Singhal, A. Lucas, P. Gringras, J. Denton and I. J. Deary (2008), 'Inspection time and cognitive abilities in twins aged 7 to 17 years: Age-related changes, heritability and genetic covariance', Intelligence, 36: 210-225.

Feinberg, J. (1986), The moral limits of the criminal law, Vol. 3: Harm to self, Oxford: Oxford University Press.

Gordon, R. A. (1997), 'Everyday life as an intelligence test: Effects of intelligence and intelligence context', Intelligence, 24: 203-320.

Gottfredson, L. S. (1997), 'Why g matters: The complexity of everyday life', Intelligence, 24: 79-132.

Gottfredson, L. S. (2004a), 'Intelligence: Is it the epidemiologists' elusive "fundamental cause" of social class inequalities in health?', Journal of Personality and Social Psychology, 86: 174-199.

Gottfredson, L. S. (2004b), 'Life, death, and intelligence', Journal of Cognitive Education and Psychology, 4: 23-46.

Gottfredson, L. S. (2005), 'Suppressing intelligence research: Hurting those we intend to help', in R. H. Wright and N. A. Cummings (eds.), Destructive trends in mental health: The well-intentioned path to harm, New York: Routledge.

Gottfredson, L. S. and I. J. Deary (2004), 'Intelligence predicts health and longevity, but why?', Current Directions in Psychological Science, 13: 1-4.

Haier, R. J. (2017), The neuroscience of intelligence, New York: Cambridge University Press.

Herrnstein, R. J. and C. Murray (1994), The bell curve: Intelligence and class structure in American life, New York: Free Press.

Hobbes, T. (1651/1996), Leviathan, or the matter, forme, \& power of a common-wealth ecclesiasticall and civill, Oxford: Oxford University Press.

Iuga, A. O. and M. J. McGuire (2014), 'Adherence and health care costs', Risk Management and Healthcare Policy, 7: 35-44.

Kahneman, D. (2011), Thinking, fast and slow, New York: Farrar, Straus and Giroux.

Kanazawa, S. (2004), 'General intelligence as a domain-specific adaptation', Psychological Review, 111: 512-523.

Kanazawa, S. (2010), 'Why liberals and atheists are more intelligent', Social Psychology Quarterly, 73: $33-57$. 
Kanazawa, S. (2013), 'Childhood intelligence and adult obesity', Obesity, 21: 434-440.

Kanazawa, S. (2014), 'Intelligence and obesity: Which way does the causal direction go?', Current Opinion in Endocrinology, Diabetes \& Obesity, 21: 339-344.

Kanazawa, S. and J. E. E. U. Hellberg (2010), 'Intelligence and substance use', Review of General Psychology, 14: 382-396.

Kirsch, I. S., A. Jungeblut, L. Jenkins and A. Kolstad (2002), Adult literacy in America: A first look at the findings of the National Adult Literacy Survey, Washington, DC: National Center for Education Statistics, U.S. Department of Education.

Mill, J. S. (1859/1991), 'On liberty', in J. Gray (ed.) On liberty and other essays, Oxford: Oxford University Press.

Neisser, U., G. Boodoo, T. J. Bouchard, Jr., A. W. Boykin, N. Brody, S. J. Ceci, D. F. Halpern, J. C. Loehlin, R. Perloff, R. J. Sternberg and S. Urbina (1996), 'Intelligence: Knowns and unknowns', American Psychologist, 51: 77-101.

O'Toole, B. I. (1990), 'Intelligence and behaviour and motor vehicle accident mortality', Accident Analysis \& Prevention, 22: 211-221.

O'Toole, B. I. and L. Stankov (1992), 'Ultimate validity of psychological tests', Personality and Individual Differences, 13: 699-716.

Rachlinski, J. J. (2006), 'Cognitive errors, individual differences, and paternalism', The University of Chicago Law Review, 73: 207-229.

Spearman, C. (1904), “'General intelligence,” objectively determined and measured', The American Journal of Psychology, 15: 201-292.

Spearman, C. (1927), The abilities of man: Their nature and measurement, London: Macmillan.

Stanovich, K. E. and R. F. West (2000), 'Individual differences in reasoning: Implications for the rationality debate?', Behavioral and Brain Sciences, 23: 645-665.

Sunstein, C. R. (2014), Why nudge? The politics of libertarian paternalism, New Haven, CT: Yale University Press.

Taylor, M. D., C. L. Hart, G. D. Smith, J. M. Starr, D. J. Hole, L. J. Whalley, V. Wilson and I. J. Deary (2003), 'Childhood mental ability and smoking cessation in adulthood: Prospective observational study linking the Scottish Mental Survey 1932 and the Midspan studies', Journal of Epidemiology and Community Health, 57: 464-465.

Thaler, R. H. and C. R. Sunstein (2008), Nudge: Improving decisions about health, wealth, and happiness, New Haven, CT: Yale University Press.

Weiser, M., S. Zarka, N. Werbeloff, E. Kravitz and G. Lubin (2010), 'Cognitive test scores in male adolescent cigarette smokers compared to non-smokers: A population-based study', Addiction, 105: 358-363.

Wennerstad, K. M., K. Silventoinen, P. Tynelius, L. Bergman, J. Kaprio and F. Rasmussen (2010), 'Associations between IQ and cigarette smoking among Swedish male twins', Social Science \& Medicine, 70: 575-581.

Wikler, D. (1979), 'Paternalism and the mildly retarded', Philosophy \& Public Affairs, 8: 377-392.

Williams, M. V., D. W. Baker, R. M. Parker and J. R. Nurss (1998), 'Relationship of functional health literacy to patients' knowledge of their chronic disease: A study of patients with hypertension and diabetes', Archives of Internal Medicine, 158: 166-172.

Williams, M. V., R. M. Parker, D. W. Baker, N. S. Parikh, K. Pitkin, W. C. Coates and J. R. Nurss (1995), 'Inadequate functional health literacy among patients at two public hospitals', JAMA, 274: 1677-1682.

Yu, Z. B., S. P. Han, X. G. Cao and X. R. Guo (2010), 'Intelligence in relation to obesity: A systematic review and meta-analysis', Obesity Reviews, 11: 656-670. 